\title{
EDITORIAL
}

\section{A BOLD statement on how to case-find moderate/ severe COPD}

\author{
Irene Steenbruggen*, Jan Zielinski ${ }^{\#}$, Peter Lange ${ }^{\tau_{,}+}$, David Price ${ }^{\S, f}$ and Joan B. Soriano**
}

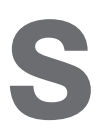
creening and case-finding strategies in chronic obstructive pulmonary disease (COPD) remain controversial, with strong opinions all over, and with any statement raising both interest and criticism. Yet, the success of an earlier diagnosis would undoubtedly produce substantial public health benefits. Expert consensus states that there are 210 million people in the world suffering from COPD [1], although these world estimates could be soon modified $[2,3]$. Whatever the number, the vast majority of individuals with COPD (70$90 \%$ ) are as yet undiagnosed [4], and therefore not receiving any medical care whatsoever. Even more importantly, many continue to smoke and/or are exposed to other risk factors. Therefore, any effective strategy to reduce COPD underdiagnosis is urgently needed.

In this issue of the European Respiratory Journal, JiTHOO et al. [5] report on a collateral work from the landmark Burden of Lung Disease (BOLD) study, this time with a particular focus on the cost-effectiveness of different population case-finding strategies for COPD. They conclude that screening by using a simple pre-bronchodilator (BD) peak expiratory flow (PEF) measurement has the potential to serve as a cost-effective way to identify individuals most likely to benefit from confirmatory spirometry. Following the guidance of an earlier report [6], these authors expand on the PEF option with a sophisticated analysis, by splitting the 14 countries and 10,472 BOLD participants into separate test and validation subsamples using a 7:3 ratio, and then by applying classification and regression tree (CART) analysis to produce a best fitting model. They propose $2.2 \mathrm{~L} \cdot \mathrm{s}^{-1} \cdot \mathrm{m}^{-2}$ as the threshold of pre-BD PEF expressed in units of litres per second per height in metres squared, to identify moderate to severe COPD. This $2.2 \mathrm{~L} \cdot \mathrm{s}^{-1} \cdot \mathrm{m}^{-2}$ threshold is proposed to have the best sensitivity versus positive predictive value and also the best cost-benefit among five different scenarios of combining PEF, questionnaires and spirometry. Put simply, they conclude that measuring PEF in everyone, without bronchodilation, and within the context of

\footnotetext{
*Pulmonary Laboratory, Isala klinieken, Zwolle, The Netherlands. "Department of Pneumonology, Medical University of Warsaw, Warsaw, Poland. "Dept of Internal Medicine, Section of Pneumonology, Hvidovre Hospital, Copenhagen, and +Dept of Public Health, Section of Social Medicine, Copenhagen University, Copenhagen, Hvidovre, Denmark. ${ }^{\varsigma}$ Academic Primary Care, University of Aberdeen, Aberdeen, and ${ }^{f}$ Optimum Patient Care Ltd and Research in Real Life Ltd, Cambridge, UK. **Programme of Epidemiology and Clinical Research, Fundación Caubet-CIMERA Illes Balears, Bunyola, Spain.
}

CORRESPONDENCE: I. Steenbruggen, Pulmonary Laboratory, Isala klinieken loc WL C2, P.O. Box 10500, 8000 GM Zwolle, The Netherlands. E-mail: i.steenbruggen@isala.nl any healthcare system, is a quick, cheap and convenient step forward to improve COPD case-finding, and the authors recommend measuring and recording of PEF as a standard vital sign much like blood pressure and weight. This new BOLD statement on how to case-find moderate/severe COPD is a major breakthrough.

We praise this BOLD initiative, in spite of some apparent limitations. The present analysis is opportunistic within a purely cross-sectional study design; the PEF manoeuvre was not obtained from a standard, common, plastic PEF-meter in a general practitioner's office, but from spirometry manoeuvres performed with the use of a validated spirometer by highly qualified technicians from established research centres, and then centrally quality-tested, something not yet possible in many settings; both PEF and spirometry measurements require maximal patient efforts, so assessing correct performance will be difficult with a standard PEF meter, resulting in somewhat falsely low values; a stringent spirometry-only criteria to identify those with significant forced expiratory volume in $1 \mathrm{~s}$ $\left(\mathrm{FEV}_{1}\right)$ impairments was considered here as the gold standard of COPD, perhaps underpinned by the concept that it is only worth diagnosing moderate to severe COPD; finally, as standard in all BOLD publications, the Hankinson's criteria for reference values were applied, while use of new, global reference equations applicable to all ages [7], might change interpretation of some estimations/variables. In addition, comparisons of peak flow with the other opportunistic approaches of microspirometry, with or without questionnaires, or population-based approaches of validated questionnaires [8,9], are not tested in this assessment. The only questionnaire-based comparison in the study is with a range of expert-derived questions.

This new BOLD recommendation might be subject to regional variability. Perhaps in some countries with already widespread use of spirometry, it will be considered a drawback to go back to PEF measurements instead of performing a pre-BD spirometry in the first place, while the PEF measurement is perhaps more feasible in less well-off countries and countries where performing spirometry will be less feasible.

We all have a duty to increase awareness of respiratory diseases in general, and COPD in particular. Lung testing, in this BOLD investigation, was considered with the following time durations: $10 \mathrm{~min}$ for the PEF or the questionnaire, and $40 \mathrm{~min}$ for the pre- and post-BD spirometry, used to confirm a clinical diagnosis of COPD, but also to make a diagnosis at an asymptomatic phase leaving ample time for smoking cessation 
opportunities by minimal intervention at the least. In many European countries, spirometry tests cost some $€ 10$ and give around eight to 20 confirmed cases of COPD per 100 tests performed in smokers not seeking medical care [10,11]. Most recently, ULRIK et al. [12] showed that if spirometry is performed in those with relevant exposures and symptoms, airways obstruction would be found in $30 \%$ of tests [12]. All health administrators would agree these are very cost-effective interventions. In contrast, oncologists have no remorse about spending much more money (and time) performing mammography and cervical smears in all females aged 45-64 yrs with a yield of only one in 100 subjects examined requiring further investigations. Similarly, cardiologists in Europe implant 3,000 pacemakers with internal defibrillators for every million population to prevent sudden death from ventricular fibrillation. Each pacemaker costs more than $€ 5,000$ (very high personnel and equipment costs not included). This amounts to $€ 15$ million for just this one cardiological procedure [13]. Taking the authors' data that half of the population aged $\geqslant 40$ is in a high-risk group for COPD we can make the following back of the envelope calculation: those aged 40-64 yrs make up roughly $30 \%$ of the total European population. A population at risk of 150,000 per million adds up to $€ 1.5$ million for screening 150,000 subjects, many of them in the moderate asymptomatic stage, with a good chance of preventing development of severe COPD. The number needed to screen and any other metrics that we apply to COPD within the 21st century should reflect the population burden and all potential gains.

Given the long-standing controversies surrounding COPD, from diagnosis itself to spirometry detection, and up to drug treatment, this new BOLD recommendation will require a higher level of evidence, and we are aware at least of two ongoing studies (UK- and US-based) aimed at validating this BOLD recommendation with rigour and standard trial methodology. Whether a pre-BD PEF of $2.2 \mathrm{~L} \cdot \mathrm{s}^{-1} \cdot \mathrm{m}^{-2}$ or lower, or any other affordable initiative to test lungs will be able to efficiently identify individuals at risk of lung disease, is worth exploring.

\section{STATEMENT OF INTEREST}

Statements of interest for P. Lange, D. Price and J.B. Soriano can be found at www.erj.ersjournals.com/site/misc/statements.xhtml

\section{REFERENCES}

1 Bousquet J, Kiley J, Bateman ED, et al. Prioritised research agenda for prevention and control of chronic respiratory diseases. Eur Respir J 2010; 36: 995-1001.

2 Murray CJ, Lopez AD, Black R, et al. Global burden of disease 2005: call for collaborators. Lancet 2007; 370: 109-110.

3 Institute for Health Metrics and Evaluation: Global Burden of Disease Study. www.globalburden.org/index.html Date last accessed: September 10, 2012.

4 Soriano JB, Zielinski J, Price D. Screening for and early detection of chronic obstructive pulmonary disease. Lancet 2009; 374: 721-732.

5 Jithoo A, Enright PL, Burney P, et al. Case-finding options for COPD: results from the Burden of Obstructive Lung Disease Study. Eur Respir J 2013; 41: 548-555.

6 Perez-Padilla R, Vollmer WM, Vázquez-García JC, et al. Can a normal peak expiratory flow exclude severe chronic obstructive pulmonary disease? Int J Tuberc Lung Dis 2009; 13: 387-393.

7 Quanjer PH, Stanojevic S, Cole TJ, et al. Multi-ethnic reference values for spirometry for the 3-95-yr age range: the global lung function 2012 equations. Eur Respir J 2012; 40: 1324-1343.

8 Frith P, Crockett A, Beilby J, et al. Simplified COPD screening: validation of the PiKo-6 in primary care. Prim Care Respir J 2011; 20: 190-198.

9 Sichletidis L, Spyratos D, Papaioannou M, et al. A combination of the IPAG questionnaire and PiKo- $6_{\mathbb{B}}$ flow meter is a valuable screening tool for COPD in the primary care setting. Prim Care Respir J 2011; 20: 184-189.

10 Zieliński J, Bednarek M, Know the Age of Your Lung Study Group. Early detection of COPD in a high-risk population using spirometric screening. Chest 2001; 119: 731-736.

11 Bednarek M, Maciejewski J, Wozniak M, et al. Prevalence, severity and underdiagnosis of COPD in the primary care setting. Thorax 2008; 63: 402-407.

12 Ulrik CS, Løkke A, Dahl R, et al. Early detection of COPD in general practice. Int J Chron Obstruct Pulmon Dis 2011; 6: 123-127.

13 Narodowy Fundusz Zdrowia (Polish Health Fund). http://nfz. gov.pl/new/index.php (website in Polish) Date last accessed: September 21, 2012. 